\title{
Wrist Drop as a Manifestation of Behçet's Disease
}

\author{
Angela Daher, Fady Haddad \\ Department of Internal Medicine, Hotel Dieu de France Hospital, Beirut, Lebanon
}

Received: 03/10/2016

Accepted: 08/11/2016

Published: 02/11/2016

How to cite this article: Daher A, Haddad F. Wrist drop as a manifestation of Behçet's disease. EJCRIM 2016;3: doi:10.12890/2016_000512.

Conflicts of Interests: The Authors declare that there are no competing interests.

This article is licensed under a Commons Attribution Non-Commercial 4.0 License

\section{ABSTRACT}

Radial mononeuropathy most commonly manifesting as wrist drop is generally secondary to penetrating trauma to the radial nerve or compression injuries. It may also involve sensory changes depending on the location of the lesion. However, it has never been described as a sign of an inflammatory process, in particular an autoimmune disease. We describe the case of a 55-year-old man who was admitted for wrist drop with bilateral paraesthesia of the upper extremities. Based on his medical history, we diagnosed Behçet's disease and subsequently neuro-Behçet's disease. He is receiving treatment with notable improvement. Neurological involvement in Behçet's disease is common but frequently undiagnosed.

\section{LEARNING POINTS}

- Clinicians must have a high index of suspicion for Behçet's disease.

- Neurological involvement must be sought after a diagnosis of Behçet's disease.

- Early treatment of neuro-Behçet's disease can stop progression to irreversible damage.

\section{KEYWORDS}

Behçet's disease, radial mononeuropathy

\section{INTRODUCTION}

Wrist drop is usually a manifestation of a radial mononeuropathy. Consequently, cervical disc disease with compression of the radial nerve must first be ruled out. Mononeuropathies are also frequently observed in multiple sclerosis, which must also be investigated. Our patient had subacute bilateral wrist drop that was at first thought to be due to these conditions. However, negative results indicated Behçet's disease (BD), which was later confirmed by a positive response to specific treatment for neuro-Behçet's disease (NB).

\section{CASE REPORT}

A 55-year old male was admitted to our hospital with new-onset rapidly evolving paraesthesia and severe pain in both hands. He had been seen 1 week previously at another hospital where a cervical MRI had demonstrated a disc herniation without compression. Electromyography (EMG) had shown evidence of bilateral carpal tunnel syndrome and so surgery on the left hand had been carried out.

At admission, vital signs were normal except for the presence of fever. The patient had a pustule where a venous catheter had been removed and examination of his skin showed many pustules and papules all over his body. He had bilateral wrist drop and was unable to voluntary extend his hands and fingers. His left hand was still swollen from surgery.

When asked about his medical history, the patient admitted a history of both oral and genital ulcers on at least three occasions in the previous year. He also often had a headache with episodes of unsteadiness. He noted some episodes of non-bloody diarrhoea. He has diabetes mellitus. 
At first, we suspected cervical disc disease due to the specific involvement of the radial nerve, but cervical MRI failed to show compression. We also considered atypical Guillain-Barré syndrome or even multiple sclerosis in light of the history of diarrhoea and the symmetrical but not ascending paraesthesia of the hands.

A complete laboratory analysis was normal except for a C-reactive protein of $64.8 \mathrm{mg} / \mathrm{l}$ and a sedimentation rate of $46 \mathrm{~mm} / \mathrm{h}$. A lumbar puncture showed 5 leukocytes/ $\mu \mathrm{l}$ (normal range between 0 and 5 leukocytes/ $\mu \mathrm{l}$ ), $0.48 \mathrm{~g} / \mathrm{l}$ of protein (normal range between 0.15 and 0.6 $\mathrm{g} / \mathrm{l}$ ) and glucose $90 \mathrm{mg} / \mathrm{dl}$ (normal range between 50 and $80 \mathrm{mg} / \mathrm{dl}$ ). Microbiological cerebrospinal fluid (CSF) investigations (gram stain, ink stain and direct antigen testing) were negative. Wide-spectrum empirical antibiotic treatment was started because of suspicion of cellulitis of the left hand, but symptoms persisted. MRI of the central nervous system showed hyperintense lesions in the potentiated T2 sequences and FLAIR, in the periventricular region and around the semioval centre, without marked enhancement after infusion with gadolinium (Figs. 1 and 2). There were no indications of sinus thrombosis or other vascular lesions on angiographic MRI.

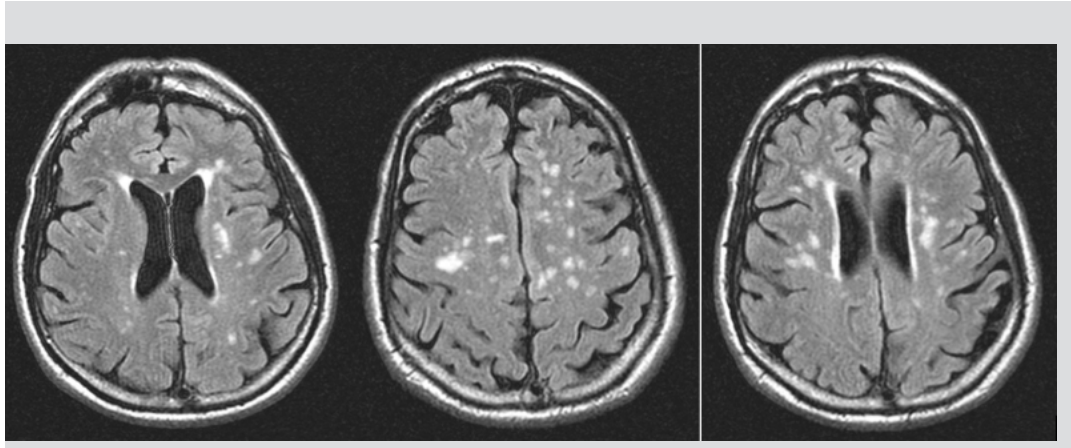

Figure 1. FLAIR sequence on MRI showing periventricular hyperintense lesions

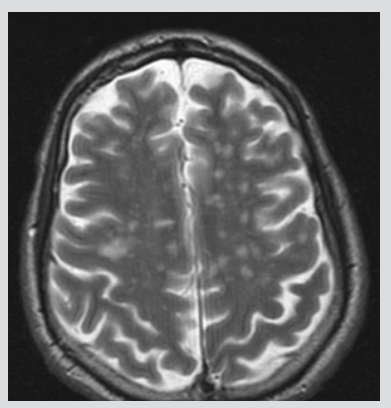

Figure 2. T2-weighted MRI showing the same periventricular lesions as seen in Fig. 1

EMG suggested a sensory polyneuropathy with motor involvement of the radial nerve. The rest of the serological, immunological and microbiological studies were negative, as was the bone marrow biopsy. A total body scan showed signs of ileitis and retroperitoneal adenopathy of less than $9 \mathrm{~mm}$. A colonoscopy confirmed the diagnosis of ulcerative ileitis.

Although the cerebral lesions suggested multiple sclerosis, the lumbar puncture results did not support multiple sclerosis or Guillain-Barré syndrome.

BD was then suspected as the patient had a history of recurrent oral and genital ulcers, papulopustular lesions of the skin, a positive pathergy test and ulcerative ileitis. Although wrist drop is unusual in this disease, we considered it part of NB and decided to treat it as such. Intravenous treatment with high-dose steroids was begun, with symptoms slightly decreasing. Cyclophosphamide was chosen for long-term management with monthly injections and started during the patient's hospitalization. Continuous physiotherapy of the hands was highly recommended.

Currently, after the first three cycles of cyclophosphamide, the patient describes less paraesthesia of his left hand along with a notable improve of the right wrist drop. The cutaneous lesions have completely disappeared. He is free of diarrhoea and has not had any headaches for the past month. He receives chronic treatment with cyclophosphamide and has not experienced disease relapse or medication-related complications.

\section{DISCUSSION}

Neurological manifestations of BD are present in $20 \neg-40 \%$ of BD patients ${ }^{[1,2]}$. They are associated with a high disease activity score and are more frequent in young males. They are rarely the first manifestation of the disease and occur approximately 5.4 years after diagnosis ${ }^{[3,4]}$.

NB manifests as cognitive and behavioural symptoms, headache, ruptured aneurysms, peripheral neuropathy, optic neuritis and vestibular involvement ${ }^{[5-7]}$. Peripheral neuropathy is generally underdiagnosed due to its subclinical pattern. It mainly includes subacute sensorimotor polyneuropathy, mononeuritis multiplex and autonomic neuropathy ${ }^{[8-10]}$. Sensory manifestations (22\%) are usually more common than motor manifestations (11\%). The sural nerve is the most frequently affected nerve in BD patients (50\% ${ }^{[11]}$.

However, in an Iranian series of Behçet's patients, one person had acute monophasic predominantly motor neuropathy resembling GuillainBarré syndrome ${ }^{[4]}$. 
Many Authors recommend conventional electrophysiological nerve conduction studies for recently diagnosed BD patients ${ }^{[12-14]}$. In fact, EMG mainly shows evidence of axonal sensorimotor neuropathy even in asymptomatic patients ${ }^{[11]}$. MRI and CSF analysis are also used in BD patients. The MRI findings include single or multiple tiny ischaemic/demyelinative lesions (iso/hypointense on T1-weighted images and hyperintense on T2-weighted images and FLAIR). CSF analysis does not show elevated CSF protein or hypoglycorrhachia, which is within the normal range ${ }^{[4]}$.

NB may be confused with multiple sclerosis as they both have a predilection to present in young people and can manifest as relapsingremitting type or with a progressive course. Moreover, they demonstrate perivascular infiltration of inflammatory cells on biopsy, which is also seen on MRI. Both respond to corticosteroid and immunosuppressant drugs but can be differentiated on CSF analysis and by the predilection for men in $\mathrm{BD}^{[4]}$.

The management of NB consists of two stages depending on whether it is an acute attack or a relapse. Acute attacks are usually treated with high-dose intravenous corticosteroids followed by maintenance treatment with oral steroids for 6-12 months. Relapses can be prevented by using an immunosuppressant such as azathioprine, mycophenolate mofetil or even cyclophosphamide if the disease is refractory to the other drugs ${ }^{[15]}$.

Our patient probably had BD for many years but was not diagnosed. His neurological presentation was at first misdiagnosed as atypical Guillain-Barré syndrome because it had a rapid onset and involved the peripheral nervous system, and as multiple sclerosis as the radial nerve was involved. EMG results supported the diagnosis of Guillain-Barré but the CSF analysis did not. The patient's cerebral MRI showed multiple hyperintense lesions on T2-weighted images consistent with the diagnosis of multiple sclerosis, but none of these lesions could explain the wrist drop. However, they could explain the headaches the patient was experiencing. Consequently, NB was considered following cerebral MRI as CSF analysis did not indicate multiple sclerosis.

A dropped wrist (motor involvement of the radial nerve) has not been described as a manifestation of BD in previous series. It could have been a coincidental finding in this patient, but the fact that he responded very well to specific treatment for NB indicates it was associated with the disease. It is important that neurological involvement (EMG or cerebral MRI) must be sought in the follow-up of all BD patients, especially since we have demonstrated that cyclophosphamide and physiotherapy changed the course of our patient's symptoms.

\section{REFERENCES}

1. Gheita TA, Samir H, Hussein H. Anti-annexin V antibodies in neuro-Behçet patients: clinical significance and relation to disease activity. Int J Rheum Dis 2012;15:e124-126.

2. Gheita TA, Bassyouni IH, Bassyouni RH. Plasma concentrations of growth arrest specific protein 6 and the soluble form of its tyrosine kinase receptor Axl in patients with systemic lupus erythematosus and Behçet's disease. J Clin Immunol 2012;32:1279-1286.

3. Talarico R, d'Ascanio A, Figus M, Stagnaro C, Ferrari C, Elefante E, et al. Behçet's disease: features of neurological involvement in a dedicated centre in Italy. Clin Exp Rheumatol 2012;30(3 Suppl72):S69-72.

4. Borhani-Haghighi A, et al. Neurological manifestations of Behçet's disease. Neurosciences 2006;11:260-264.

5. Dutra LA, de Souza AW, Alessi H, Guedes Bde V, Braga-Neto P, Pedroso JL, et al. Cognitive impairment in Brazilian patients with Behcet's disease occurs independently of neurologic manifestation. J Neurol Sci 2013;327:1-5.

6. Kale N, Agaoglu J, Icen M, Yazici I, Tanik O. The presentation of headache in neuro-Behcet's disease: a case-series. Headache 2009;49:467-470.

7. Siva A, Kantarci OH, Saip S, Altintas A, Hamuryudan V, Islak C, et al. Behcet's disease: diagnostic and prognostic aspects of neurological involvement. J Neurol 2001;248:95-103.

8. Namer IJ, Karabudak R, Zileli T, Ruacan S, Kücükali T, Kansa E. Peripheral nervous system involvement in Behçet's disease. Eur Neurol 1987;26:235-240.

9. Takeuchi A, Kodama M, Takatsu M, Hashimoto T, Miyashita H. Mononeuritis multiplex in incomplete Behçet's disease: a case report and the review of the literature. Clin Rheumatol 1989;8:375-380.

10. Aksoyek S, Aytemir K, Ozer K, Ozcebe O, Oto A. Assessment of autonomic nervous system function in patients with Behçet's disease by spectral analysis of heart rate variability. J Auton Nerv Sys 1999;77:190-194.

11. Hammad M, Sharaf D, El-Shafey A, Nasr M. Peripheral nerve involvement in Behcet's disease; an electrophysiological study. Egyptian Rheumatologist 2014;36:195-199.

12. Akbulut L, Gur G, Bodur H, Alli N, Borman P. Peripheral neuropathy in Behçet disease: an electroneurophysiological study. Clin Rheumatol 2007;26:1240-1244.

13. Atasoy HT, Tunc TO, Unal AE, Emre U, Koca R, Esturk E, et al. Peripheral nervous system in patients with Behçet disease. Neurologist 2007;13:225-230.

14. Yurdakul S, Yazici H. Behçet's syndrome. Best Pract Res Clin Rheumatol 2008;22:793-809.

15. Kürtüncü M, Tüzün E, Akman-Demir G. Behçet's disease and nervous system involvement. Curr Treat Options Neurol 2016;18:19. 